ear three times daily and a complete recovery was obtained in ten days.

It must be said here that in neither of the acute cases was there left any impairment of the hearing. As a means of treating acute suppurative otitis media (after perforation has occurred) I can very highly recommend the injection into the cavity of the middle ear by means of the Eustachian canal of a small quantity of a 5 per cent. solution of mercurol. By such treatment a more rapid and effective cure is usually gained than by any other, its only disadrantage being that it almost of necessity should be left to the specialist to carry out. That one does obtain extremely good results from mercurol in chronic suppurative otitis media cannot be denied, but at the same time for my own part I would not, as before stated, consider this drug to be to any extent superior to, say, perchloride of mercury or carbolic acid. The following may be taken as an example of the treatment of chronic otitis media.

OASE 2.-A woman, aged 31 years, had suffered from discharge from both ears since, at the age of six years, she had had scarlet fever. The discharge was very offensive. On the right side there was a perforation in the posterior superior quadrant and one also in the anterior inferior, while on the left side there was a sinus leading into the antrum with a small posterior perforation on a level with the tip of the handle. 5 per cent. of mercurol was ordered three times daily as an injection. At the end of six weeks the discharge on the left side had entirely ceased and was reduced to an inodorous, clear, watery discharge on the right side. The mercurol solution was then reduced to $2 \frac{1}{2}$ per cent. and the patient was seen again in three weeks' time, when the discharge had entirely ceased on the right side.

As an example of the use of mercurol in diffuse inflammation of the external meatus the following case may be mentioned.

CASE 3.-A man, apparently of gouty habit, came to me complaining of discharge from one ear. The meatus was entirely occluded by diffuse swelling; the discharge was thin and very purulent-that is to say, there was acute gouty affection (eczema) of the ear. He was given mercurol in a 5 per cent. solution and immediately obtained the greatest relief from the irritation. The swelling in the canal disappeared extremely rapidly, and, what is much more important, the mercurol seemed in this instance to have effectually prevented contraction.

The following is an instance of the use of mercurol in chronic suppuration of the maxillary antrum.

CASE 4. - The patient was a man, aged 38 years, who was under the care of Mr. E. T. M. Tunnicliffe who brought him to me with the following history. The patient had had a nasal discharge for six months from the left side which had all along been offensive at times. On pressure within the nostril offensive pus could be evacuated by the patient. On examination of the left nose a large projection was seen below the inferior turbinated bone. This was soft and elastic, giving a feeling of a dense wall cyst, from which pus could be made to exude at the posterior part if firm pressure were applied. This was incised and some drachms of extremely offensive pus were evacuated, and on examination the abscess cavity was found to be continuous with the maxillary sinus, the lower part of the internal bony wall of the antrum being entirely absorbed. The cavity was irrigated with 5 per cent. of mercurol and was packed with iodoform gauze. In three weeks' time there was practically no discharge and absolutely no smell; the latter, I was informed, had never reappeared after the first washing with mercurol. The percentage of mercurol was now reduced to $2 \frac{1}{2}$, which was kept up as a matter of precaution for another three weeks, when the opening was allowed to close, perfect cure having been obtained.

CASE 5.-The patient, a female, had suffered from chronic suppuration of the maxillary antrum for at least 18 months. The antrum was opened through the alveolus on the right side at the side of the first molar which had been removed some time previously. There was a fair amount of pus in the antrum and the lining membrane was much thickened as detected by the probe. Irrigation with mercurol ( 1 per cent.) was carried out regularly twice daily with the result that there was a complete cure in six weeks.

I have used mercurol ( 2 per cent.) twice after operations, one being a double ossiculectomy and the other an operation for opening the frontal sinus. The wounds in both cases remained in an absolutely satisfactory and aseptic condition, though one would frequently find it necessary to change from so bland and unirritating an antiseptic to one having the strongly caustic properties of 5 per cent. of carbolic acid, especially where much ulceration remains, the tendency of which to secrete it is frequently desirable to overcome. I have also irrigated the frontal sinus with it viâ the infundibulum with satisfactory results, but as these cases have been amongst hospital patients and I have been unable to see them sufficiently often I cannot attribute a cure to mercurol in this respect, though the general impression I derived was that had I been able to use it sufficiently often, say daily, it would have given better results.

With regard to chronic suppuration of the middle ear I have only quoted one case. From the small number of cases in which the drug was systematically used the general results may be apparently slightly above the average obtained by other antiseptics. But, as before remarked, it is the anatomical and mechanical obstruction to the penetration of any particular remedy to the seat of disease that renders this ailment so intractable. So to claim for mercurol any peculiar and specific action in this disease would be, in my opinion, absurd. My general impression is that mercurol is the least irritating efficient antiseptic with which I am acquainted, being possessed of properties which commend it highly, especially as a lotion for the irrigation of cavities such as the maxillary sinus.

Harley-street, W.

\section{A CASE OF MORPHIA-POISONING TREATED BY ATROPINE.}

\section{By EDWARD GROUND, M.D. CANTAB.}

As there is a certain difference of opinion among anthorities on toxicology as to the value of atropine in morphiapoisoning I think the following case may possibly be of interest to readers of THE LANCET.

A few weeks ago, at about 2 P.M., I was summoned to see a man, aged 61 years. His wife told me that he had been in bed for two or three days suffering from an attack of influenze and that shortly before she sent for me he had been seized with faintness which alarmed her very much. I found him in bed, looking rather sleepy (he had had a good dinner); his face was flushed, his pulse was quick (about 100), and his pupils were contracted. On being questioned he strenuously denied having taken any opiate and his wife who had been with him while he was having his dinner said she was quite sure that he could not have taken any without her knowledge. I was sent for again in a hurry at 5 P.M., an empty one-ounce bottle, labeled " Liq. morph. hydrochlor.," having been found in his room. When I arrived (at 5.30) I found him very drowsy and looking very pale, sweating profusely, and with very contracted pupils. He then admitted that he had taken one ounce of solution of hydrochlorate of morphia in his brandy-and-soda at dinner-time, under the impression that he was taking two grains of morphia. After a little difficulty I persuaded him to take an emetic, but he only brought up a little tea which he had taken shortly before. I then gave him a hypodermic injection of a thirty-third of a grain of sulphate of atropia and three grains of permanganate of potash in pill every three hours, with the idea of oxidising any unabsorbed morphia that might remain in the intestinal canal. At 7 P M., although he could only be roused with difficulty, his general condition had undergone a marked improvement. The pallor had given place to a dist inct flushing of the face, the profuse sweating had stopped and the skin was dry. the pupils were less contracted, and the pulse had improved in tone and in volume. The injection was repeated then, and again at 9.30 P.M., when he was quite insensible but otherwise about the same. At 11 P.M. another injection of atropine was given, with one-thirtieth of a grain of sulphate of strychnia, as his pulse was inclined to fail. $\mathrm{He}$ remained quite insensible, but his breathing never became stertorous, until about 12.30 A.M. when, after vigorous shaking, he began sligktly to raise his eyelids and ti show signs of returning consciousness. At 4.30 A.M., after con stant shakings, moving of his arms and legs. with artificial respiration, he became conscious and gradaally recovered.

A great many cases of opium- and morphia-poisoning successfully treated with atropine have been reported in which the dose of poison was very mulh larger than in this case. A case has been oescribed by Dr. D. T. Playfair, ${ }^{1}$ in 
which a woman, aged 37 years, took 30 grains of acetate of morphia, a fact which was not discovered until three hours afterwards. Four injections of atropine, each of one-fortieth of a grain, were given, but the recovery of the patient was attributed to the prolonged use of oxygen gas with artificial respiration, all natural respiratory movements having ceased for several hours. Mr. Percy Pope ${ }^{2}$ records a case of recovery in a girl, aged 19 years, after a hypodermic injection of 12 grains of morphia. The treatment consisted in the administration of four grains of atropine in doses of one-twentieth of a grain at short intervals during 12 hours and in artificial respiration, strong coffee, and attempts to rouse the patient. Cruse describes the case of an infant, one week old, who was accidentally poisoned by a grain of morphine. The comatose condition that resulted remained unaffected by various treatments for several hours until a quarter of a grain of atropine was administered and the dose repeated after an interval of half an hour. Recovery was complete in 38 hours and no unpleasant symptoms attended the administration of such large doses of atropine. From the marked improvement in my patient I should be inclined to regard atropine as a valuable remedy in opiumpoisoning; but there appears to be one difficulty, and that is to know when the limit of safety has been reached with regard to the amount of atropine to be used. The action of morphia and atropine is not exactly antagonistic, the former acting centrally and the latter peripherally. According to Dr. J. Dixon Mann, "Morphia slows the heart's action by excitation of the vagus at its origin in the brain; atropine quickens the heart by paralysing the terminations of the vagi and the inhibitory ganglia in the beart. ...... Opium acting centrally contracts the pupils; atropine paralyses the terminals of the oculo-motor nerves. Opium causes sweating by stimulating the central nerve apparatus concerned; atropine arrests it by paralysing the nerve terminals in the sweat glands." Ultimately, however, the effects of the two poisons become mutual, both paralysing the motor and sensory nerves, atropine especially paralysing the heart and opium the respiratory apparatus. Some caution, therefore, is required in using the antidote. Dr. A. P. Luff recommends that it be given in frequently repeated doses until half a grain has been given, and this should provide a fair margin of safety. My patient took about four and onethird grains of morphia which is not a very large dose, and one-eighth of a grain of atropine was given as an antidote, which, I believe, contributed largely to his recovery. There is one point that is rather impressed on the mind in considering this question and that is that however large the dose of opium or morphia may be there need be no despair, with the help of atropine, oxygen, and artificial respiration, of rescuing from death the person poisoned even after the poison has become thoroughly absorbed.

Maidstone.

\section{Climital a}

\section{MEDICAL, SURGICAL, OBSTETRICAL, AND THERAPEUTICAL.}

\section{A CASE OF ARSENIOAL BEER POISONING.}

By J. HaRold BaIley, M.B. Vict.

ON Oct. 9th, 1900, I was called in to attend a married woman, aged 41 years, residing in Pendleton, she having slipped and sprained her left ankle. Rest and the application of lead and opium lotion to the injured joint were prescribed. The swelling around the joint subsided and the pain, which was severe, abated somewhat, but at the end of a week the patient began to complain of pains and tingling in the left foot, and she was unable to stand upright and was obliged to remain altogether in bed. Cramps in the calves of both legs were next complained of, and the feet and legs became exceedingly painful to pressure on any part of them; she also complained of the weight of the bed-clothes and of being unable to sleep at night owing to the intensity of the pains. After another week the patient noticed that her hands were becoming

2 The Lancet, March 17th, 1894, p. 669. affected, saying that they felt numb to the touch, thougb painful sensations like "pins and needles" were present. She could not use her hands, moving the fingers with difficulty. Her appetite began to fail, the tongue became slightly coated, and vomiting of yellowish bile occasionally occurred. Before being confined to bed the patient had been accustomed to bave beer for supper and she admitted having taken a glass or two since. Hearing late on Nov, 20th that Dr. W. S Reynolds had detected arsenic in beer in Manchester I called at the patient's house on the morning of Nov. 21st and sent out for a jug of the beer which she was in the habit of drinking ; this was obtained from the shop whence she had been getting her beer, and on its being analysed by Mr. William Kirkby, F.L.S., of Owens College, it was found to contain 0.14 grain per gallon of $\mathrm{As}_{4} \mathrm{O}_{6}$. A sample of urine from the patient failed to show the presence of arsenic, though in the case of another patient of mine who had drunk the same beer and was suffering from symptoms of arsenical poisoning the urine showed a faint trace of arsenic. The condition of the patient became gradually worse, the weakness of the limbs increasing, and there being in addition considerable general wasting. On making a detailed examination on Nov. 29th the following state of affairs was noticed. The patient lay on her right side in a drowsy, heavy condition, with the eyes half open and the knees drawn up. She opened her eyes slowly when asked to do so. She could recognise me, mentioning my name. She complained of her head, saying that it felt as though drums were playing in the street. Dark brownish pigmentation of the skin was present on the neck, the axillæ, the abdomen, the thighs, and the legs. There was flaky desquamation of the skin over the lower part of the abdomen. Over the calves of the legs the skin was roughened and desquamating. The legs and hands could be moved slightly without the patient being roused, but on making more extended movements she complained of pain. The left foot was dropped and the skin was thickened; on the right foot keratosis was well marked, especially over the heel. The patellar reflex was absent on both sides. The tongue was red and moist, the pupils reacted readily to light, the eyes were somewhat watery, but there was no nasal discharge. The heart sounds were regular but feeble, the first sound was hardly to be detected. The pulse was 100 per minute and exceedingly feeble. The respirations were 24 per minute there was slight movement of the diaphragm. The chest moved as a whole without much lateral expansion. The temperature was normal. During the five days ending on Dec. 4th the patient's condition remained much the same though more nourishment was taken and the comatose state was not so well marked.

Pendleton.

\section{SYMPTOMS OF ARSENICAL POISONING PRODUCED}

\section{IN A YOUNG CHILD BY DRINKING BEER.}

BY JoHn BRown, M.D. VICT., D.P.H., MEDICAL OFFICER OF HEALTH OF BACUP.

DURING the recent epidemic of peripheral neuritis, now proved to have arisen from the drinking of arsenicated beer $I$ have seen no reference to any cases observed in very young children. Such must be of very rare occurrence, as it is to be hoped that parents do not generally allow young children to drink beer. Moreover, if a case occurred in a child it. would most probably not be easily detected, as it is a condition one would hardly expect in a young child. On Nov. 27tb, however, whilst attending a patient affected with peripheral neuritis my suspicions were aroused to the case which I now record, and I was led to suspect that the child was suffering from arsenical beer poisoning by the fact that the father had peripheral neuritis. Dr. Kelynack, to whom, with $\mathrm{Mr}$. Kirkby, is due the eredit of being the first to announce to the profession the true source of the arsenic, very kindly came to Bacup to see the patient with me. He went over the case very thoroughly and expressed his opinion that it was undoubtedly a distinct but mild case of peripheral neuritis due to arsenical beer. The case being unique I have made a few notes briefly recording the more important features.

The patient was a bonny-looking little girl, aged two years. She had been unwell for some days, suffering from pains in 